\title{
БРИТАНО-ЯПОНСКОЕ СТРАТЕГИЧЕСКОЕ ПАРТНЁРСТВО В УСЛОВИЯХ БРЕКЗИТА
}

\begin{abstract}
Аннотация. В условиях брекзита Великобритания значительно интенсифицировала политический диалог с Токио, поскольку нуждается в демонстрачии союзов с «естественньми партнёрами» в разных регионах мира. Перспектива брекзита без сделки вызывает серьёзное беспокойство в Стране восходящего солнща, поскольку для азиатских производителей рынок Соединённого Королевства - «ворота» в Евросоюз. Лондон рассматривает партнёрство с Японией как «плачдарм» для укрепления своих стратегических позищий в Индо-Тихоокеанском регионе. В последние годы активно развивается диалог двух стран по безопасности и военно-техническое взаимодействие. Токио и Лондон в разной мере обеспокоены растушим влиянием Китая, однако оба государства заинтересовань в расширении торгово-инвестиционного сотрудничества с Поднебесной.
\end{abstract}

Ключевые слова: Соединённое Королевство, Япония, переговоры, военное сотрудничество, торгово-экономические отночения, США, Южно-Китайское море, Китай, Индо-Тихоокеанский регион, брекзит.

\section{Брекзит и торгово-экономические интересы Японии}

С окончания Второй мировой войны Япония и Великобритания выступают союзниками в продвижении либерального мирового порядка. В 1973 г. Соединённое Королевство стало частью европейской интеграции, а японский бизнес начал активно инвестировать в британскую экономику, рассматривая туманный Альбион как «ворота», через которые можно легко получить доступ на европейский рынок. Сегодня Токио - пятый крупнейший инвестор для Соединённого Королевства (объём вложений свыше 40 млрд ф.ст.) после США, Германии, Франции и Нидерландов.

В январе 2019 г. министр иностранных дел Великобритании Дж. Хант подчеркнул геостратегическое сходство островных государств, которые располагают минимальными природными ресурсами, но имеют огромный экономический потенциал. Сегодня около одной тысячи японских компаний работают в Соединённом Королевстве, обеспечивая трудовыми местами более 150 тыс. человек. В 2017 г. британский экспорт в Страну восходящего солнца увеличился на $12 \%$ и составил 13,5 млрд ф.ст. ${ }^{1}$

В Токио с тревогой восприняли результаты референдума о членстве Великобритании в Европейском союзе, поскольку брекзит напрямую угрожает интересам японского бизнеса. В 2018 г. на полях саммита Группы Двадцати в Аргентине премьер-министр С. Абэ предостерёг Т. Мэй: выход из европейской интеграции без сделки негативно отразится на экономиках

(C) Годованюк Кира Анатольевна - кандидат политических наук, старший научный сотрудник Центра британских исследований Отдела страновых исследований ИЕ РАН. Aдрес: 125009, Россия, Москва, ул. Моховая, д. 11, стр. 3. E-mail: kira.godovanyuk@gmail.com.

DOI: http://dx.doi.org/10.15211/vestnikieran320198994

${ }^{1}$ Japanese Prime Minister's visit is a chance to celebrate our friendship with like-minded nations: article by Jeremy Hunt. URL: https://www.gov.uk/government/speeches/japanese-prime-ministers-visit-is-a-chance-to-celebrate-ourfriendship-with-like-minded-nations-article-by-jeremy-hunt (дата обращения: 05.06.2019). 
их стран ${ }^{1}$. В январе 2019 г. в Лондоне на переговорах с главой британского Кабинета (накануне вступления в силу Договора об экономическом партнерстве между Токио и Брюсселем) японский лидер отметил, что «весь мир желает избежать брекзита без сделки» ${ }^{2}$.

В случае неупорядоченного «развода» Британии и ЕС бизнес Японии будет вынужден переориентировать хозяйственные цепочки на континентальную Европу (вплоть до переноса автомобильных заводов «Ниссан», «Тойота» и «Хонда» ${ }^{3}$ из Великобритании в другие страны Евросоюза). При таком сценарии Соединённое Королевство ожидают значительные экономические убытки и потеря рабочих мест.

Идеологи брекзита предлагают компенсировать издержки за счёт самостоятельной торговой политики и договоров о свободной торговле с мировыми экономическими центрами. Впервые Т. Мэй выразила намерение заключить такое соглашение со Страной восходящего солнца в апреле 2017 г. $^{4}$, чему была посвящена встреча лидеров двух стран в Токио в августе 2017 г. $^{5}$

Хотя правительство тори последние два года проводило интенсивную предварительную работу, ясности по параметрам потенциальных сделок пока нет. Все контрагенты Соединённого Королевства, включая Японию, занимают выжидательную позицию. Во-первых, Лондон не может вести переговоры по торговому соглашению до завершения брекзита. Во-вторых, когда Европейский союз и Великобритания определят параметры будущих торговых отношений, Токио сможет просчитать экономические издержки для национального бизнеса и будет готов обсуждать условия торгового соглашения с Лондоном. Фактически любые сделки Даунинг стрит, 10 с третьими странами будут зависеть от договорённостей с Брюсселем. Так, в январе 2019 г. Япония подписала выгодное торговое соглашение с Евросоюзом, а значит, на переговорах с Лондоном будет исходить из собственных договорённостей с Брюсселем. Задача Токио - поддержать статус-кво торгово-экономического сотрудничества с Великобританией и сохранить свободный доступ к рынку товаров, капитала и инвестиций Евросоюза, а также унифицированным техническим стандартам, регулирующим продажу товаров и услуг.

В апреле 2019 г. в ходе встречи с главой Форин Офиса Дж. Хантом премьер-министр С. Абэ одобрил решение Лондона избежать «развода» с Европейским союзом без сделки и продлить срок переговоров с Брюсселем до 31 октября 2019 г. ${ }^{6}$ Однако исход брекзита остаётся неопределённым, что, естественно, отражается на настроениях инвесторов и торговых партнёров.

\section{Стратегическое сотрудничество в области обороны}

Япония и Великобритания - стратегические партнёры США в области обороны и безопасности в Азии и Европе соответственно («обрамляют» Евразию с востока и запада). Сле-

\footnotetext{
${ }^{1}$ Japanese PM Shinzō Abe urges Theresa May to prevent a no-deal Brexit. URL: https://www.itv.com/news/2018-1201/japanese-pm-urges-theresa-may-to-prevent-a-no-deal-brexit/ (дата обращения: 05.06.2019).

2 Brexit: Japan's PM says «wish of whole world» to avoid no-deal. URL: https://www.bbc.com/news/uk-politics46826345 (дата обращения: 05.06.2019).

${ }^{3}$ В феврале 2019 г. руководство японского автомобильного коншерна «Хонда» объявило о закрытии к 2021 г. завода на юго-западе Британии (единственное на территории ЕС). хотя и не подтвердило. что решение связано с неопределённостью вокруг брекзита. В марте 2019 г. японский автоконшерн «Тойота» предупредил. что прекратит производство в Британии, если выход из Европейского союза состоится на неблагоприятных для него условиях. ${ }^{4}$ PM statement following talks with Japanese Prime Minister Abe: 28 April 2017. URL: https://www.gov.uk/govern ment/speeches/pm-statement-following-talks-with-japanese-prime-minister-abe-28-april-2017 (дата обращения: 05.06. $2019)$.

${ }^{5}$ UK and Japan: Prime Minister's visit 2017. URL: https://www.gov.uk/government/news/uk-and-japan-prime-minis ters-visit-2017 (дата обращения: 05.06.2019).

5 Abe asks UK Foreign secretary Jeremy Hunt to minimize Brexit impact on Japan firms and world. URL: https:// www.japantimes.co.jp/news/2019/04/15/business/abe-asks-u-k-foreign-secretary-jeremy-hunt-minimize-brexit-impactjapan-firms-world/ (дата обращения: 05.06.2019).
}

Научно-аналитический вестник ИЕ РАН, 2019, №3 
довательно, Токио и Лондон считают друг друга «естественными союзниками». Страны высоко ценят взаимодействие в таких международных форматах, как Группа семи и двадцати, в том числе антитеррористическое взаимодействие, противодействие пиратству и совместный вклад в обеспечение региональной безопасности. За последнее десятилетие значительно продвинулось сотрудничество двух стран в оборонной сфере.

Ещё в январе 2004 г. стороны подписали Меморандум в отношении оборонного сотрудничества (Memorandum Relating to Defence Cooperation). В апреле 2012 г. премьер-министр Великобритании Д. Кэмерон и его японский коллега согласовали общее заявление с амбициозным названием «Лидирующее стратегическое партнёрство для глобального процветания и безопасности» ${ }^{1}$.

В июне 2012 г. на полях «Шангри-Ла диалога» ${ }^{2}$ началась работа на основе полномасштабного Меморандума о сотрудничестве в области безопасности, подписанного министрами обороны двух стран.

С 2015 г. стороны развивают диалог глав оборонных и внешнеполитических ведомств в формате «2+2» (не менее интенсивно в таком формате сотрудничают Япония и РФ). В Лондоне в ходе третьего раунда переговоров в декабре 2017 г. глава МИД Б. Джонсон и министр обороны Г. Уильямсон и их японские коллеги подтвердили намерение продолжать совместные исследования новой управляемой ракеты класса «воздух-воздух». Главы ведомств также согласовали трёхлетний план сотрудничества по вопросам обороны ${ }^{3}$. Перечисленные задачи отвечают целям концепции «Глобальная Британия» и японской стратегии «Активного содействия миру» ${ }^{4}-$ амбициозным заявкам двух стран на новую роль в международных отношениях ${ }^{5}$.

Страны активизировали военно-морскую кооперацию и совместные учения. Например, в 2016 г. четыре британских истребителя Тайфун были задействованы наряду с самолётами Японии, США и Австралии в маневрах Guardian North с целью снизить риск военной угрозы со стороны Северной Кореи ${ }^{6}$.

Итогом двусторонней встречи Т. Мэй и С. Абэ в августе 2017 г. стали две Декларации по вопросам сотрудничества в области безопасности и обеспечения благосостояния, а также два специальных Совместных заявления. Лидеры зафиксировали схожие позиции по острым вопросам международной повестки, в первую очередь, по ядерной программе Северной Кореи. В 2017 г. премьер-министр Великобритании побывала на заседании СНБ Японии (ранее только премьер-министр Австралии принимал участие в работе этого органа).

Ещё в январе 2016 г. министр обороны Соединённого Королевства М. Фэллон говорил, что США привержены тесному военно-стратегического альянсу с Японией и Британией, ко-

\footnotetext{
${ }^{1}$ См. Подробнее: Joint statement by the prime ministers of the UK and Japan: A Leading Strategic Partnership for Global Prosperity and Security - 10 April 2012. URL: http://japan.kantei.go.jp/noda/diplomatic/201204/10uk_e.html.

2 «Шангри-Ла диалог» - ежегодный межправительственный форум по безопасности в Азиатско-Тихоокеанском регионе под эгидой Международного института стратегических исследований (IISS) при участии министров обороны и других военных руководителей 28 государств АТР.

${ }^{3}$ UK and Japan strengthen defence ties. The Defence Secretary and Foreign Secretary met their Japanese counterparts at Greenwich Naval College. URL: https://www.gov.uk/government/news/uk-and-japan-strengthen-defence-ties--2 (дата обращения: 05.06.2019).

4 «Активное содействие миру» (Proactive Contribution to Peace) - установка стратегии национальной безопасности Японии от 2013 г. Токио намерен играть более активную роль в достижении мира и предотвращении международных угроз, чтобы обеспечить мировой порядок и стабильную международную среду как условие собственной безопасности и развития.

5 UK-Japan Foreign and Defence Ministerial Meeting 2017 - Joint Statement. URL: https://www.gov.uk/govern ment/news/uk-japan-foreign-and-defence-ministerial-meeting-2017-joint-statement (дата обращения: 05.06.2019).

${ }_{6}$ UK sends Typhoons to Japan for joint drills to strengthen security ties. URL: https://www.theguardian.com/ world/2016/oct/14/uk-sends-raf-typhoons-to-japan-joint-drills-china (дата обращения: 05.06.2019).
}

Научно-аналитический вестник ИЕ РАН, 2019, №3 
торый обеспечит безопасность в регионе ${ }^{1}$. Сегодня британское руководство прилагает значительные усилия и для создания подобного альянса в треугольнике Лондон-Токио-Канберра с целью укрепить собственные стратегические позиции в Индийском и Тихом океанах.

\section{Британо-японские отношения в контексте Индо-Тихоокеанского региона}

Форин-офис сформулировал три приоритетных региона для Британии после брекзита: Северная Америка и США, Европа (ЕС и его ближайшие соседи), а также Индо-Тихоокеанский регион (ИТР $)^{2}$. Этот термин появился в стратегических документах Великобритании и заявлениях лидеров вслед за американскими, японскими, индийскими и австралийскими коллегами ${ }^{3}$.

В подтверждение курса на «Глобальную Британию» в течение 2018 г. Даунинг стрит, 10 разместил вблизи Японских островов три военно-морских корабля (HMS Albion, Sutherland, Argyll $)^{4}$.

Фрегат Argyll прибыл в Японию в декабре 2018 г. для первых совместных морских учений после манёвров вблизи Австралии в рамках «Договора пяти держав по обороне» 5 . Токио приветствует растущий интерес Соединённого Королевства к ИТР в условиях формирующейся новой архитектуры безопасности в регионе.

В январе 2019 г. по итогам встречи с С. Абэ в Лондоне премьер-министр Британии объявила, что до конца текущего года ещё один военный корабль HMS Montrose будет дислоцирован у японских берегов ${ }^{6}$. Стороны также договорились увеличить количество военных учеуче-ний в воздухе, на суше и на море в предстоящем году.

Кроме участия в совместных военных учениях, манёвры Королевских ВМС должны обеспечить контроль за соблюдением санкционного режима СБ ООН в отношении КНДР и поддержать «свободу навигации» (FONOPS) ${ }^{7}$.

\footnotetext{
${ }^{1}$ America, Japan and the UK: A New Three Way Alliance against China? URL: https://nationalinterest.org/feature/ america-japan-the-uk-new-three-way-alliance-against-china-20019 (дата обращения: 05.06.2019).

${ }^{2}$ Global Britain. Sixth Report of Session 2017-19. Published on 12 March 2018. URL: https://publications. Parlia ment.uk/pa/cm201719/cmselect/cmfaff/780/780.pdf P. 10 (дата обращения: 15.02.2019).

${ }_{3}$ Термином ИТР принято обозначать геополитическое пространство Индийского и Тихого океанов, в котором пересекаются интересы Китая и целого ряда региональных акторов. Одна из важных характеристик региона значительное увеличение торговых потоков между Восточной Азией, Южной Азией и Ближним Востоком. Термин ИТР был предложен в январе 2007 г. сотрудником индийского Института оборонных исследований и анализа Г. Кхурана. В августе 2007 г. премьер-министр С. Абэ заявил о «слиянии двух морей большой Азии» и призвал создать на её просторах «дугу свободы и процветания». Концепцию взял на вооружение Вашингтон, который рассчитывает, что четырёхсторонний неформальный блок QUAD (США, Япония, Австралия, Индия) будет обеспечивать безопасность в регионе в противовес китайскому влиянию. Военная активность в ИТР обращает на себя внимание и европейских акторов, например, Великобритании, Франции и Германии. Khurana G. «Security of Sea Lines: Prospects for India-Japan Cooperation», Strategic Analysis 31.01.2007; Confluence of the Two Seas" Speech by H.E.Mr. Shinzo Abe, Prime Minister of Japan at the Parliament of the Republic of India. URL: http://www. mofa.go.jp/region/asia-paci/pmv0708/speech-2.html (дата обращения: 05.06.2019).

${ }^{4}$ HMS Sutherland arrives in Japan in effort to curb North Korea's evasion of sanctions. URL: URL: https://www.tele graph.co.uk/news/2018/04/12/hms-sutherland-arrives-japan-effort-curb-north-koreas-evasion/ (дата обращения: 05.06. $2019)$.

5 «Договор пяти держав по обороне» (Five Power Defence Arrangements) - серия оборонных соглашений Соединённого Королевства и четырёх членов Содружества - Австралии, Новой Зеландии, Малайзии, Сингапура (1971 г.). ${ }^{6}$ PM statement alongside PM Shinzo Abe of Japan: 10 January 2019. URL: https://www.gov.uk/government/speeches/
pm-statement-alongside-pm-shinzo-abe-of-japan-10-january-2019 (дата обращения: 05.06.2019).
FONOPS (Freedom of Navigation Operations) - операции по обеспечению свободы судоходства в Южно-Китай-
Китай-ском море, которые, по задумке Вашингтона, должны стать вызовом территориальным претензиям Ки-
тая расширить военно-стратегическое присутствие в районе Парасельских островов. С 2015 г. военные суда
США регу-лярно проходят вблизи спорных островов в поддержку «свободы судоходства», а фактически в це-
лях военного демарша. 31 октября 2018 г. десантно-вертолётный корабль-док Королевских ВМС НMS Аlbion
прошёл вблизи Парасельских островов. Этот военно-морской манёвр стал первым прямым сигналом Лондона о
} Научно-аналитический вестник ИЕ РАН, 2019, №3 
Последнее, по мнению Лондона и Вашингтона, должно стать ключевым компонентом глобальной системы, «основанной на правилах», и противодействия «подрывной деятельности» Китая в регионе.

Военно-морские манёвры Лондона в ИТР призваны продемонстрировать характеристики новейших военных разработок Великобритании. Очевидно, что торговля оружием может стать дополнительным аргументом Соединённого Королевства в продвижении оборонного сотрудничества со странами региона.

Несмотря на риторику о «Глобальной Британии», в рамках которой Лондон намерен усилить присутствие в Азии, пока не ясно, каковы перспективы страны в этой части света. Для Соединённого Королевства отношения с ЕС и его ближайшими соседями, равно как и дальнейшее развитие «особых отношений» с США останется главным приоритетом. Азиатское направление будет развиваться, скорее всего, по остаточному принципу. Кроме того, Британия до сих пор не определила стратегию в отношении Китая, но считает его перспективным торговым партнером после брекзита ${ }^{1}$.

Лондон рассматривает альянс с Японией - ключевым союзником в северо-восточной Азии как плацдарм для расширения влияния на весь ИТР, что важно для восстановления репутационных потерь, связанных с выходом из Европейского союза.

\section{Выводы}

На фоне приближающегося брекзита Соединённому Королевству крайне важно продемонстрировать наличие у него влиятельных и надёжных друзей вне ЕС, среди которых США, Япония и партнёры по Альянсу «Пять глаз» приобретают приоритетное значение.

Страна восходящего солнца как один из крупнейших инвесторов в экономику Великобритании обеспокоена угрозой неупорядоченного брекзита без сделки, одновре́менно с этим стороны укрепляют двустороннее сотрудничество в оборонной сфере в ИТР, что отвечает стратегическим интересам обеих стран.

Лондон разделяет обеспокоенности Токио в связи с военно-стратегическим усилением Пекина в регионе. Страны настороженно воспринимают китайскую «Инициативу пояса и пути» как инструмент геополитического влияния Поднебесной в Азии, Африке и Европе, однако считают Китай важнейшим торговым партнёром в эпоху брекзита и усиления протекционистских настроений Д. Трампа. Япония, в свою очередь, в последние годы значительно нарастила уровень торговли с Пекином и заинтересована в ней.

Будет ли «российский фактор» определять динамику британо-японского сотрудничества? Стороны договорились придерживаться твёрдой позиции в отношении «дестабилизирующей» деятельности России в Сирии и на Украине, но у них нет полного взаимопонимания в отношении Москвы. Например, Япония не выслала российских дипломатов в ответ на инцидент в Солсбери в марте 2018 г., как это сделали многие союзники Лондона. Британские власти обеспокоены «близоруким» курсом Токио на потепление российско-японских отношений» ${ }^{2}$.

поддержке «свободы судоходства».

${ }^{1}$ Годованюк К.А. Аналитическая записка «Золотая эра» британо-китайских отношений. Quo vadis? 25.04.2019. URL: http://www.instituteofeurope.ru/images/uploads/analitika/2019/an163.pdf.

${ }^{2}$ The UK and Japan Forging a Global and Proactive Partnership. Final report of the UK Japan Global Seminar series. Edited by John Nilsson Wright. May 2019. URL: https://www.chathamhouse.org/sites/default/files/2019-05-29\%20UK \%20Japan\%20Global\%20Partnership.pdf. P. 8.

Научно-аналитический вестник ИЕ РАН, 2019, №3 


\section{Список литературы}

Лексютина Я.В. Роль Китая в стратегии «Свободный и открытый Индо-Тихоокеанский регион» Д. Трампа. Вестник РУДН. Серия: Международные отношения. Т.19, №1, 2019. С. 22-34.

\section{References}

Hemmings J. Global Britain in the Indo-Pacific. The Henry Jackson Society. May 2018. URL: https://henryjacksonsociety.org/wp-content/uploads/2018/05/Global-Britain-in-the-Indo-PacificWEB.pdf.

The UK and Japan Forging a Global and Proactive Partnership. Final report of the UK Japan Global Seminar series. Edited by John Nilsson Wright. May 2019. URL: https://www. chathamhouse.org/sites/default/files/2019-05-29\%20UK\%20Japan\%20Global\%20Partnership.pdf.

Leksyutina Ya.V. Rol' Kitaya v strategii «Svobodnyj i otkrytyj Indo-Tihookeanskij region» D. Trampa. Vestnik RUDN. Seriya: Mezhdunarodnye otnosheniya, Vol.19, №1, 2019. C. 22-34.

Joint statement by the prime ministers of the UK and Japan: A Leading Strategic Partnership for Global Prosperity and Security - 10 April 2012. URL: http://japan.kantei.go.jp/noda/diplomatic/ 201204/10uk_e.html.

\section{UK-Japan Strategic Partnership in Light of Brexit}

Author. Kira Godovanyuk, Candidate of Sciences (Politics), Senior Research Associate at the UK Studies Center, Department of Countries Studies, Institute of Europe, Russian Academy of Sciences. Address: 11-3, Mokhovaya str., Moscow, Russia, 125009. E-mail: kira.godovanyuk@gmail.com.

Abstract. The paper considers the UK policy towards Japan defined as its key ally in Asia. In light of upcoming Brexit, Great Britain tends to intensify the political dialogue with Tokyo in order to demonstrate alliances with «natural partners» all over the world. The option of a no-deal Brexit deeply concerns the Land of the Rising Sun since Japanese producers consider the UK as the main gateway to the EU. London in turn looks at Japan as a platform for further strengthening its strategic position in the Indo-Pacific region. The UK-Japan security dialogue is actively developing along with military cooperation. Although the rise of China poses concerns for Japan and the UK to a different extent, both countries appreciate significant economic opportunities offered by trading with Beijing.

Keywords: UK, Japan, negotiations, military cooperation, trade and economic cooperation, USA, China, South-China Sea, Indo-Pacific region, Brexit

DOI: http://dx.doi.org/10.15211/vestnikieran320198994 